\title{
Long Vowels and Nasal-consonant Sequences in Kisa
}

\author{
Emily Ayieta Ondondo \\ Department of Linguistics, Languages and Literature, Jaramogi Oginga Odinga University of Science and Technology \\ (JOOUST), P.O. Box 210-4060, Bondo, Kenya
}

\begin{abstract}
Nasal Consonant (NC) sequences, in Bantu languages, and the long vowels preceding them remains a puzzle in Bantu literature and research. This paper provides a descriptively oriented analysis of the relationship between long vowels and nasal consonant sequences in Kisa, a dialect of Luhya, a Bantu language spoken in Khwisero Constituency Western Province, Kenya. The data used in this paper was generated by the author as a native speaker of Kisa. The central descriptive fact is that NC sequences in words consisting of native Kisa morphemes are usually, but not obligatorily, preceded by long vowels. ${ }^{1}$ As such, NC sequences usually appear as part of an overall VVNC sequence. This pattern is widely found in Bantu languages, and the modelling of this preference for VVNC sequences has been a significant topic in phonological research on Bantu languages. Kisa provides evidence against the predominant analysis of the VVNC preference in Bantucompensatory lengthening. The paper shows that compensatory lengthening does not provide a well-motivated analysis of Kisa.
\end{abstract}

Index Terms-Bantu, Kisa, Nasal Consonant Sequences, compensatory lengthening

\section{INTRODUCTION}

The analysis of the origin of the long vowels preceding $\mathrm{NC}$ sequences in Bantu languages as compensatory lengthening was initially proposed by Clements (1986, p. 47, 52-53). Clements' original proposal was in terms of CV phonology. Its interpretation in moraic analyses (Downing, 2005, p. 185, Hubbard, 1995, p. 244, Hyman, 1992, p. 256, Maddieson \& Ladefoged, 1993, p. 274-278, Tak, 2011, p. 134) is illustrated in (1).

(1)<smiles>[10BH][10BH][In]</smiles>

As shown in (1), the compensatory lengthening analyses posit that the $\mathrm{N}$ is moraic in input representation. The moraic linkage of the $\mathrm{N}$ is not maintained in the output. Most analyses do not provide an explicit motivation for the non-maintenance of the moraic linkage of the N. Tak (2003, p. 507) proposes that phonological requirements, such as constraints against codas, and constraints against moraic consonants; provide a motivation for the change in linkage. In order to preserve the mora of the $\mathrm{N}$, it is linked to the preceding vowel, thereby causing lengthening. In other words, the preceding long vowel is exhaustively explicable in terms of phonological requirements targeting the $\mathrm{N}$ in NC sequences. This is the principal advantage of the compensatory lengthening analysis. It provides a single phonological analysis for the distribution of VVNC sequences.

There is debate as to the output representation of the NC sequence. As indicated in (1), under the Clements analysis, the output is a singleton complex segment - a pre-nasalized stop. Hubbard (1995, p. 251) proposes that the NC sequence is a cluster, and that there is language specific variation in the nature of moraic linkage in the output.

(2)
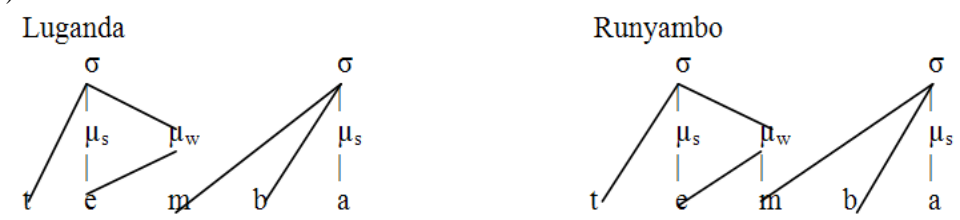

While Hubbard and Clements differ in their analyses of the NC sequence, both propose that it is a syllabic onset

Downing (2005, p. 186-190) argues against the compensatory lengthening analysis. She provides evidence that a VVNC output is cross-linguistically widespread, and that compensatory lengthening analyses cannot account for this preference in a number of non-Bantu languages. She surveys phonetic factors potentially motivating a VVNC output.

${ }^{1}$ There are other Bantu languages where NC sequences may be preceded by short vowels: e.g. Kimatuumbi (Odden, 1996, p. 136). 
She suggests that vowels may be lengthened to avoid being confounded with a following nasal. She suggests also that the duration of homorganic NC sequences may be more similar to single segments than clusters. ${ }^{2}$ The combination of these two factors further favours VVNC outputs. She proposes the input and output representations in (3) for NC sequences in Bantu languages (2005, p. 197).

(3)

Input<smiles>[AlH]C[AlH]</smiles>

$\mathrm{V} \quad \mathrm{N} \quad \mathrm{C} \ldots$

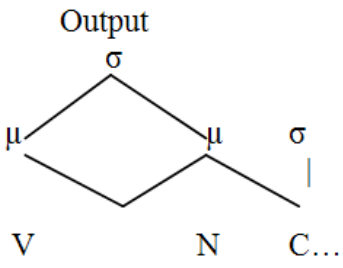

Under Downing's analysis, the $\mathrm{N}$ is exhaustively syllabified as a coda.

The paper supports Downing's proposal that VVNC is an independent target, and that compensatory lengthening analyses cannot satisfactorily account for this target. The Kisa evidence against compensatory lengthening is different in nature to that considered by Downing. The Kisa evidence is morpho-phonological in nature, and concerns the factors conditioning the distribution of VVNC sequences in Kisa. The VVNC preference in Kisa is not solely governed by phonological factors. It is also partially governed by two morphological factors. First, the VVNC preference shows a greater consistency of attainment root-internally, than across affixal boundaries. Second, in some environments involving affixation, if a standard stem input would result in output form with a VNC sequence rather than a VVNC sequence, then an alternate non-standard stem is selected such that the output does involve a VVNC sequence.

The first factor, the distinction between root-internal domains and domains involving affixation, is a standard, independently supported component of general phonological theory. Its interaction with the VVNC preference does not affect the viability of compensatory lengthening analyses. The second factor, alternate stem choice to attain a VVNC output, is not a standard component of general phonological theory. It is this factor that the paper is principally concerned with. It provides the evidence that VVNC is a distinct target in Kisa, independent of any compensatory lengthening analysis.

In any consideration of morphologically governed data, the first question that arises is whether or not there is evidence that the patterns are productive. If patterns show significant lexicalization and/or irregularity, then they may not fall within the purview of synchronic morpho-phonological analysis. The paper shows that the VVNC preference in the native Kisa lexicon involves only minimal lexicalisation and/or irregularity. Further, it provides evidence from recent loan vocabulary that the preference for VVNC sequences over VNC sequences, including those involving alternate stem choice, is synchronically active in Kisa. Consequently, any synchronic analysis of Kisa must include the VVNC preference, and alternate stem selection to attain this preference.

While the paper supports the generality of Downing's analysis, it does not adopt her specific formal representations, as set out in (3). There are two reasons why the paper does not adopt her formal proposal, or indeed any other formal proposal. First, the potential alternate analyses require detailed phonetic and phonological evaluation of a range of issues: e.g. comparative length of NC vs singleton C; perceptual confoundability of VN sequences vs VVN sequences; motivations for the assignment of syllable boundaries. The proper evaluation of this range of issues is beyond the scope of this paper. Second, it is the aim of this paper to provide the data in as theory-neutral a fashion as possible, such that it is available for (re-)analysis in a variety of frameworks.

\section{KISA SEGMENTAL INVENTORY AND ORTHOGRAPHY}

The IPA representation of the Kisa consonantal inventory is presented in Table 1

TABLE 1:

KISA CONSONANTAL INVENTORY - IPA

\begin{tabular}{|c|c|c|c|c|c|c|c|}
\hline & Bilabial & Labio-dental & Alveolar & Palato-alveolar & Palatal & Velar & Glottal \\
\hline Stops & $\mathrm{p}$ & & $\mathrm{t}$ & & & $\mathrm{k}$ & \\
\hline Affricates & & & ts & t & & & \\
\hline Fricatives & $\beta$ & $\mathrm{f}$ & $\mathrm{s}$ & $\int$ & & $\mathrm{x}$ & $\mathrm{h}$ \\
\hline Nasals & $\mathrm{m}$ & & $\mathrm{n}$ & $\mathrm{n}$ & & $\mathrm{y}$ & \\
\hline Trill & & & $\mathrm{r}$ & & & & \\
\hline Lateral & & & 1 & & & & \\
\hline Glides & W & & & & $\bar{j}$ & & \\
\hline
\end{tabular}

Table 2 presents the practical orthography representation of the Kisa consonantal inventory.

\footnotetext{
${ }^{2}$ All NC clusters in Kisa are homorganic.
} 
TABLE 2:

KISA CONSONANTAL INVENTORY - PRACTICAL ORTHOGRAPHY

\begin{tabular}{|l|l|l|l|l|l|l|l|}
\hline & Bilabial & Labio-dental & Alveolar & Palato-alveolar & Palatal & Velar & Glottal \\
\hline Stops & $\mathrm{p}$ & & $\mathrm{t}$ & & & $\mathrm{k}$ \\
\hline Affricates & & & $\mathrm{ts}$ & $\mathrm{ch}$ & & \\
\hline Fricatives & $\mathrm{b}$ & $\mathrm{f}$ & $\mathrm{s}$ & $\mathrm{n}$ & $\mathrm{sh}$ & $\mathrm{kh}$ & $\mathrm{n}$ \\
\hline Nasals & $\mathrm{m}$ & & $\mathrm{nd}$ & & $\mathrm{n}$ & $\mathrm{n}$ \\
\hline Nas-Stop & $\mathrm{mb}$ & & $\mathrm{nz}$ & $\mathrm{nj}$ & & \\
\hline Nas-Aff & & & $\mathrm{r}$ & & & & \\
\hline Trill & & & $\mathrm{l}$ & & & \\
\hline Lateral & & & & & & \\
\hline Glides & $\mathrm{w}$ & & & & \\
\hline
\end{tabular}

Kisa has a classic five vowel system /a, e, i, o, u/. Length is contrastive for all five vowels (See section $B$ ).

\section{PARTS-OF-SPEECH AND MORPHOlOGICAL TEMPLATES}

Kisa shows standard Bantu morphological patterns. It has three principal parts-of-speech: nominals, particles, and verbs. The basic morphological template for singular common nouns, plural common nouns, and plural proper nouns is set out in (4).

(4) Locative/Augment-Class marker-Root

The class system for common nouns is set out in Table 3.

TABLE 3:

COMMON NOUN CLASS SYSTEM

\begin{tabular}{|c|c|c|c|c|c|c|c|}
\hline \multicolumn{4}{|c|}{ Singulars } & \multicolumn{4}{|c|}{ Plurals } \\
\hline & AUG & $\mathrm{Cl}$ & Semantic Domains & & AUG & $\mathrm{Cl}$ & Semantic Domains \\
\hline 1 & $0-$ & $\mathrm{mu}-$ & Humans & 2 & a- & ba- & Regular plurals of class 1 \\
\hline 3 & o- & mu- & Trees, plants & 4 & e- & mi- & Regular plurals of classes 3 and 20 \\
\hline $5 a$ & $\emptyset-$ & lii- & \multirow[t]{2}{*}{ Fruits } & \multirow[t]{2}{*}{6} & \multirow[t]{2}{*}{ a- } & \multirow[t]{2}{*}{ ma- } & \multirow{2}{*}{$\begin{array}{l}\text { Regular plurals of class } 5 \text {, liquid } \\
\text { masses }\end{array}$} \\
\hline $5 b$ & $\mathrm{e}-$ & li- & & & & & \\
\hline 7 & e- & shi- & Nouns of manner & 8 & e- & bi- & Regular plurals of class 7 \\
\hline $9 \mathrm{a}$ & i- & $\varnothing-$ & Loans & $10 \mathrm{a}$ & e- & tsi- & Regular plurals of class $9 \mathrm{a}$ \\
\hline $9 \mathrm{~b}$ & i- & ny- & $\begin{array}{l}\text { No clear semantic domain } \\
\text { associations }\end{array}$ & $10 \mathrm{~b}$ & $\varnothing-$ & tsiiny- & Regular plurals of class $9 \mathrm{~b}$ \\
\hline $9 \mathrm{c}$ & i- & ny- & \multirow{2}{*}{$\begin{array}{l}\text { Gerunds with the meaning 'style or } \\
\text { way of doing things' }\end{array}$} & $10 \mathrm{c}$ & $\varnothing-$ & tsiiny- & \multirow[t]{2}{*}{ Regular plurals of class $9 \mathrm{c} / \mathrm{d}$} \\
\hline $9 \mathrm{~d}$ & i- & nz- & & $10 \mathrm{~d}$ & $\varnothing-$ & tsiinz- & \\
\hline 12 & a- & kha- & Diminutives & 13 & o- & ru- & Regular plurals of class 12 \\
\hline 15 & o- & khu- & Infinitives/gerunds & 14 & o- & bu- & Abstract entities, mass nouns \\
\hline 20 & o- & ku- & Augmentatives & & & & \\
\hline
\end{tabular}

It may be noted that the Augment prefix is $\emptyset$ - in Classes 5a and Classes $10 \mathrm{~b} / \mathrm{c} / \mathrm{d}$, and that the Class prefix is $\boldsymbol{\emptyset}$ - in Class 9a. There is only one environment where the Augment prefix does not appear with common nouns. This is with the interrogative shiina 'which', as illustrated in (5).

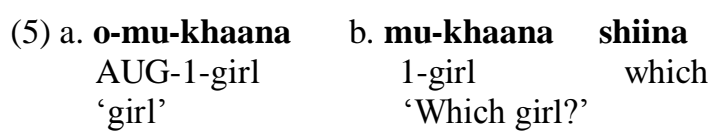

In all other environments, the Augment appears. This includes citation, so the citation form of 'girl' is o-mu-khaana and not mu-khaana. Singular proper nouns differ from other nouns. They do not take either an Augment or a Class marker. The template for singular proper nouns is set out in (6).

(6) Locative-Root

The morphological structure of verbs follows general Bantu patterns, as summarized in (7).

(7)

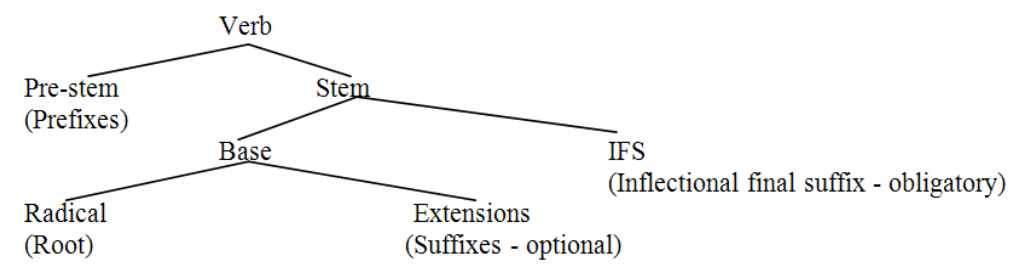

Particles do not permit affixation, and consist of just a root. 
This section is principally concerned with the distribution of long vowels. However, it begins by examining vowel hiatus, as hiatus resolution is an important contributor to the appearance of long vowels in output forms.

\section{A. Vowel Hiatus Resolution}

Resolution of vowel hiatus is a complex matter, and its analysis is not germane to the purposes of this paper. The general patterns found within root and affixal domains in Kisa are set out in Table 4.

TABLE 4:

HIATUS RESOLUTION

\begin{tabular}{|l|l|l|}
\hline Vowel 1 & Vowel 2 & Hiatus resolution \\
\hline i & e & yee \\
\hline i & a & yaa \\
\hline i & o & yoo \\
\hline i & u & yuu \\
\hline u & i & wii \\
\hline u & e & wee \\
\hline u & a & waa \\
\hline u & o & woo \\
\hline a & i & ee \\
\hline a & e & ee \\
\hline a & o & oo \\
\hline a & u & oo \\
\hline
\end{tabular}

There is one other pattern of hiatus resolution - complete progressive assimilation. This pattern is found only with the $1 \mathrm{sgO}$ prefix iny-.
(8) Output b-a-am-bis-a *b-e-em-bis-a
Input b-a-iny-bis-a
3plS-FARP-1sgO-hide-IND
'They hid me.'
(9) Output ba-la-mu-un-dool-er-a *ba-la-mwi-in-dool-er-a
Input ba-la-mu-iny-dool-er-a
3plS-HODF-3sgO-1sgO-pick-APPL-IND
'They will pick him/her up for me.'

The only other /i/ initial prefix, the reflexive i- shows standard hiatus resolution, as illustrated by the comparison of 0 with 0 .
$\begin{array}{cc}\text { (10) Output } & \mathbf{b}-\boldsymbol{e}-\boldsymbol{e} \text {-bis-a } \\ \text { Input } & \mathbf{b}-\boldsymbol{a}-\boldsymbol{i}-\mathbf{b} \text {-bis-a }\end{array}$
3plS-FARP-REFL-hide-IND
'They hid themselves.'

\section{B. Phonology and Phonotactics of Vowel Length}

Vowel length is contrastive for lexical morphemes in Kisa, as illustrated in Table 5.

TABLE 5:

LEXICAL VOWEL LENGTH CONTRASTS

\begin{tabular}{|c|c|c|c|}
\hline sab-a & 'Ask for something!' & i-m-bale & 'new shoots' \\
\hline saab-a & 'Wash!' & i-m-baale & 'gravel' \\
\hline mer-a & 'Shoot up!' & a-ma-bere & 'millet' \\
\hline meer-a & 'Become drunk!' & a-ma-beere & 'milk' \\
\hline sir-a & 'Fence!' & i-shima & 'rust' \\
\hline siir-a & 'Jump over!' & i-shiima & 'respect' \\
\hline bol-a & 'Rot!' & o-lu-kosi & 'neck of a fowl' \\
\hline bool-a & 'Speak!' & o-lu-koosi & 'favouritism' \\
\hline ruk-a & 'Rule/govern!' & lii-kuku & 'grass (sp.)' \\
\hline ruuk-a & 'Jump!' & lii-kuuku & 'pigeon' \\
\hline
\end{tabular}

Vowel length is also contrastive for grammatical morphemes.

\section{(11) b-a-shi-kul-a b-aa-shi-kul-a
3plS-FARP-7O-buy-IND 3plS-REMP-7O-buy-IND}

'They bought it. (Some time back)' 'They bought it. (Long time ago)'

Long vowels may appear in adjacent syllables, both within roots, and across the prefix - root boundary.

(12) Ø-lii-tiimooni

AUG-5a-demon

'demon'

There is one general restriction on long vowels in Kisa - vowels at root and word boundaries are always short. This includes all cases where a root initial vowel is followed by an NC sequence. There are 33 noun roots and 21 verb roots 
in Kisa that begin with a vowel followed by a NC sequence. The sequence ${ }_{\mathrm{Rt}}$ [VNC is not therefore a marginal pattern in Kisa. All vowel-initial prefixes which can appear word-initially have an initial short vowel. Consequently, vowels are always short in word-initial position.

\section{NC SEQUENCES AND MORPHOLOGICAL STRUCTURE}

Kisa has both tautomorphemic and heteromorphemic NC sequences.

\section{A. Tautomorphemic NC Sequences and Preceding Vowel Length}

Tautomorphemic NC sequences are very common in Kisa, but they are overwhelmingly found in non-initial positions. There are only 12 morphemes from the native Kisa lexicon with an initial NC sequence.

(13) a. Nominal roots: mbuuya 'personal name', mbootso 'niece', ngalashiinga 'bet'

b. Particles: mbula'so that', mbushiina 'why', mberi 'before', mbaanga 'awkward'

c. Clitics: $\mathbf{m b u}=$ '(so) that', =mbu 'like that, in that way'

d. Prefixes: nz- 'class 9d', ndi- ' $1 \mathrm{sgS}$ ', nz- ' $1 \mathrm{sgO}$ '

Of the morphemes listed in (13), all can appear word-initially (i.e. without overt prefixation), except for ngalashiinga 'bet', =mbu 'like that, in that way', and nz- '1sgO'. There are six loan nominal roots from Swahili with initial NC sequences.

(14) ndeeche 'plane', ndiimu 'lime', ngaano 'wheat', ngaasi 'ladder', ngamya 'camel', nguume 'fist'

Subject to the constraint against long vowels at root and word boundaries, vowels preceding NC sequences in roots are long. There are four exceptions, the two colour terms in (15), and the two particles in (16).

(15) ranzaayi 'red', rambiiya 'orange'

(16) nende 'and', shinga 'like'

There are three affix allomorphs where a tautomorphemic NC sequence is preceded by a vowel. Two involve a long vowel, and one involves a short vowel.

(17) tsiinz- 'class 10d', inz- '1sgO', -VVng 'Imperfective'

\section{B. Tautomorphemic NC Sequences and Preceding Vowel Length in Loans}

Loan words show the same patterns as the native vocabulary. If the vowel preceding the NC sequence is the rootinitial vowel, then it is short.

(18) embulooy-a

employ-sgS

'Employ!'

Otherwise, vowels preceding NC sequences are long, regardless of the orthography or pronunciation in the source language.

(19) koombiit-a

compete-sgS

'Compete!'

The paper takes this as evidence that VVNC is a synchronically active phonological target in Kisa.

\section{Heteromorphemic NC Sequences}

Heteromorphemic NC sequences most commonly arise in Kisa when one of the nasal-final prefix allomorphs in (20) is prefixed to a morpheme beginning with a stop or the bilabial fricative $/ \beta /$.

(20) ny- 'Class 9b/c', tsiiny- 'Class $10 \mathrm{~b} / \mathrm{c}$ ', eny- ' $1 \mathrm{sgS}$ ', iny- ' $1 \mathrm{sgO}$ ', ny- ' $1 \mathrm{sgO}$ '

The prefix nasal assimilates in place. The following stop or bilabial fricative assimilates in manner, and is realized as a voiced stop. These assimilation processes are productive and apply to loans.

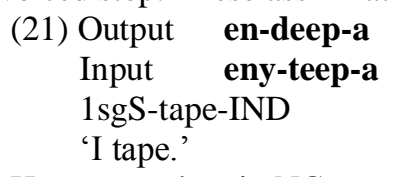

Heteromorphemic NC sequences also arise from two unproductive assimilation processes. One process involves /1/. If one of the prefixes in (20) is attached to a native root with an initial /l/, then the output is an NC sequence.

\section{(22) Output en-dol-a}

Input eny-lol-a

$1 \mathrm{sgS}$-see-IND

'I see.'

This process is subject to Meinhof's Law. If the following consonant is a nasal or an NC sequence, then the heteromorphemic NC sequence is reduced to an $\mathrm{N}$.

(23) Output e-num-ae-noond-a

Input eny-lum-a eny-loond-a

1sgS-bite-IND 1sgS-follow-IND 
'I bite.' 'I follow.'

Neither Meinhof's Law nor the assimilation are attested in loans, which show only deletion of the prefix-final nasal and preservation of the /l/.The other unproductive process is found only with roots which begin with the trill /r/ when they take the Class $9 \mathrm{~b}$ and Class $10 \mathrm{~b}$ prefixes.

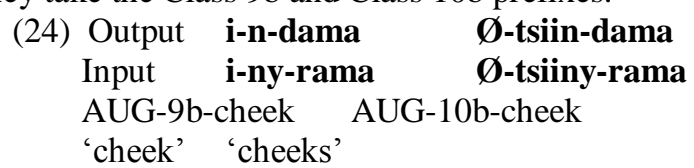

This process is not attested with loans or elsewhere in the native lexicon. Otherwise, the prefix final nasal is deleted and the trill is preserved.

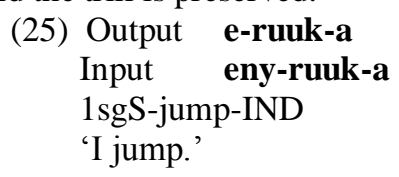

\section{THE VVNC PREFERENCE AND AFFIXATION}

As previously stated, all vowel-initial prefixes which can appear in word-initial position have an initial short vowel, even when followed by an NC sequence. This conforms to the general constraint against word-initial long vowels.

The distribution of vowel length before NC sequences elsewhere in affixal domains is complex. The critical data for the analysis of the VVNC preference comes from the Locative forms of Class $9 \mathrm{~b} / \mathrm{c} / \mathrm{d}$ nouns. The general prefix complex for Classes $9 b$ and $9 c$ is i-ny-'AUG-9b/c', and that for $9 d$ is i-nz- 'AUG-9d'. In Locative prefixation, the Locative prefixes, which are listed in (26), replace the Augment prefix.

(26) ha- 'by/at', khu- 'on', mu- 'in'

Consequently, the predicted Locative prefix forms for Class 9b/c/d nouns are those listed in (27).

(27) ha-ny- 'by/at-9b/c', ha-nz- 'by/at-9d', khu-ny- 'on-9b/c', khu-nz- 'on-9d', mu-ny- 'in-9b/c', mu-nz- 'in-9d'

However, in the actual forms, the vowels in the prefix complex are long, as in (28).

(28) haa-ny- 'by/at-9b/c', haa-nz- 'by/at-9d', khuu-ny- 'on-9b/c', khuu-nz- 'on-9d', muu-ny- 'in-9b/c', muu-nz'in-9d'

As assimilation across the prefix-root boundary in Classes $9 \mathrm{~b}$ and $9 \mathrm{c}$ produces an $\mathrm{NC}$ sequence, the final output word forms have a long vowel before an NC sequence.

(29) Class 9b muu-n-do 'in the bucket'

Class 9c muu-n-gul-a 'in the buying style'

In Class 9d forms, the prefix supplies an NC sequence.

(30) Class 9d muu-nz-ay-a 'in the plucking style'

At first sight, these Locative forms might appear to support a compensatory lengthening analysis. However, as we will see, there are a number of reasons why a compensatory lengthening analysis cannot be supported.

Rather, the paper proposes that these forms involve the selection of an alternate non-standard stem for locative prefixation. Specifically, the paper proposes that they involve the selection of the citation form as the stem for locative prefixation. The regular stem selection is illustrated in (31), and the proposed alternate stem selection in (32).

(31) Locative-stem $[\text { Class marker-Root }]_{\text {stem }}$

(32) Locative-stem[Augment-Class marker-Root $]_{\text {stem }}$

The derivation of Class $9 \mathrm{~b} / \mathrm{c} / \mathrm{d}$ Locative forms is illustrated in (33).

(33) mu-u-n-do mu-u-n-gul-a mu-u-nz-ay-a mu-i-ny-to mu-i-ny-kul-a mu-i-nz-ay-a in-AUG-9b-bucket in-AUG-9c-buy-INF in-AUG-9d-pluck-INF

'in the bucket' 'in the buying style' 'in the plucking style'

As illustrated, this proposal involves non-standard total progressive assimilation, which is otherwise only attested with the /i/ initial prefix iny- ' $1 \mathrm{sgO}$ '. The forms according to standard assimilation are set out in (34).
(34) mw-ii-n-do
mu-i-ny-to
khw-ii-n-do
he-e-n-do
'in the bucket' 'on the bucket' 'by the bucket'

Though this proposal involves both non-standard stem selection and non-standard assimilation, the paper nonetheless shows that it provides a better motivated analysis of the relevant Kisa data than a compensatory lengthening analysis.

Given that Locative prefixes are outer prefixes, the analysis of the Kisa 9/b/c/d Locative data under compensatory lengthening models would be that compensatory lengthening applies in all affixal domains, subject to independently motivated factors which might inhibit lengthening in particular environments. The general Kisa constraint against long vowels in word-initial position would be an example of such an independently motivated factor.

By contrast, the analysis proposed here predicts that long vowels will fail to appear in the two environments listed in (35) and (36). 
(35) When alternate stem selection is inhibited by an independently motivated factor

(36) When there is no alternate stem

Both these environments are attested in Kisa. The paper begins by considering the environment in (35). In this case, the data involves the interrogative shiina 'which'. This is the only form which consistently blocks the appearance of the Augment prefix (Section III). Under the proposal, where the citation form is selected as the alternate stem, the additional mora required for a long vowel in the Class 9b/c/d Locatives is supplied by the Augment prefix. As shiina blocks the Augment prefix, Class 9b/c/d Locative constructions involving shiina should not involve long vowels. As illustrated in (37), this is the case.

(37) Class 9b mundo shiina 'in which bucket?'

Class 9c mungula shiina 'in which buying style?'

Class 9d munzaya shiina 'in which plucking style?'

It is not evident how the data in (37) could be accommodated under a compensatory lengthening analysis. The distribution of phonologically motivated patterns may be affected by particular aspects of prosodic or syntactic structure. However, they are not affected by the appearance or non-appearance of individual lexemes.

The second environment in (36) involves two distinct sets of data. One set concerns the Locative forms of singular proper noun roots with initial NC sequences.

\section{(38) ha-mbootso ha-mbuuya}

by-niece by-personal name

'by the niece' 'by Mbuuya'

As shown, these Locatives have a short vowel and not a long vowel. Under the analysis this paper proposes, this follows from the fact that singular proper nouns do not show substantive prefixation for either Class or Augment. Consequently, there is no alternate stem which can be selected. The root is the only stem. Again, it is not evident how this data would be accommodated by a compensatory lengthening analysis. In phonological terms, the environment in (38) does not appear distinguishable from that found with Class 9b/c/d Locatives. Consequently, compensatory lengthening analyses would predict that there should be lengthening in the environment in (38).

The other set involves noun class prefixes attaching to a root with an initial NC sequence.

$\begin{array}{clllll}\text { (39) } 5 & \text { Ø-lii-ngalashiinga } & \text { 'bet' } & 6 & \text { a-ma-ngalashiinga } & \text { 'bets' } \\ 12 & \text { a-kha-ngalashiinga } & \text { 'little bet' } & 13 & \text { o-ru-ngalashiinga } & \text { 'little bets' } \\ 20 & \text { o-ku-ngalashiinga } & \text { 'big bet' } & 4 & \text { e-mi-ngalashiinga } & \text { 'big bets' }\end{array}$

As shown in 0 if a root with a morpheme-initial NC sequence takes a class prefix, then that prefix maintains its inherent quantity - short prefixes remain short. Under the analysis proposed here, this follows from the fact that noun class prefixes are inner prefixes, which attach directly to the root. Consequently, there is no alternate stem for them to select. Alternate stem selection is only an option for outer affixes.

By contrast, there is no evident reason why lengthening should fail to occur under a compensatory lengthening analysis. One hypothesis might be that the Locative prefixes and the Class prefixes constitute distinct phonological domains, and can therefore show distinct phonological patterns. Compensatory lengthening would apply to the Locative prefixes, but not to the Class prefixes. However, any proposal of this nature would face a major problem: compensatory lengthening would show a discontinuous domain distribution. The template for common nouns is repeated in (40) for convenience.

(40) Locative/Augment-Class marker-Root

If the long vowels in the Locative forms of Class $9 \mathrm{~b} / \mathrm{c} / \mathrm{d}$ nouns result from compensatory lengthening, then it would be necessary to propose that compensatory lengthening applied to roots, and to the outer Locatives, but not to the inner Class markers. This would be a most unusual domain distribution for a phonological process.

\section{Alternate Stem Selection and VVNC in Loans}

As discussed in section I, in considering morphologically governed patterns, information on productivity is important. In this section, I present data from recent loan vocabulary establishing that alternate stem selection to attain a VVNC output is synchronically active. The principles for the assignment of loans to noun classes are set out in (41).

(41) a. If the referent is human, then assign the noun to Class 1

b. If the referent is non-human, but belongs to a lexical domain which has a prototypical association with a particular Class, then assign the loan to that Class.

c. If the loan is a Swahili word, then assign the loan to the phonotactically and semantically similar class in Kisa. $\mathrm{d}$. If none of the preceding factors apply, then assign the loan to Class 9a.

It is the interaction between principles (c) and (d) which is of interest. Principle (c) gives priority to structural similarity considerations over default assignment.

(42) o-mu-furechi m-fereji (Swahili)

AUG-3-faucet 3-faucet

'faucet'

Semantically, 'faucet' has no clear association to any class in Kisa, and therefore it should be assigned to Class 9a in terms of semantics. However, the structural similarities favour assignment to Class 3 . There is also the factor that most Class 3 Swahili forms have an initial heterorganic cluster, a strong signal to morphologically divide the initial cluster. 
The situation where a Swahili loan has an initial homorganic cluster is more complicated. Let us consider the Swahili form n-dege '9-plane'. This form is structurally similar to the Kisa Class 9b, and this is the class to which such loans are assigned. However, there are some morphophonemic complications, as (43) - (45) illustrate.

\begin{tabular}{|c|c|c|c|c|c|}
\hline (43) $9 b$ & i-n-do & 'bucket' & $10 b$ & Ø-tsiin-do & 'buckets' \\
\hline 12 & a-kha-to & 'little bucket' & 13 & o-ru-to & 'little buckets' \\
\hline 20 & o-ku-to & 'big bucket' & 4 & e-mi-to & 'big buckets' \\
\hline (44) $9 \mathrm{~b}$ & i-Ø-ndeeche & 'plane' & $10 \mathrm{~b}$ & Ø-tsii-ndeeche & 'planes' \\
\hline 12 & a-kha-ndeeche & 'little plane' & 13 & o-ru-ndeeche & 'little planes' \\
\hline 20 & o-ku-ndeeche & 'big plane' & 4 & e-mi-ndeeche & ‘big planes’ \\
\hline 45) $9 a$ & i-Ø-kalaamu & 'pen' & $10 \mathrm{a}$ & e-tsi-kalaamu & 'pens' \\
\hline 12 & a-kha-kalaamu & 'little pen' & 13 & o-ru-kalaamu & 'little pens' \\
\hline 20 & o-ku-kalaamu & ‘big pen’ & 4 & e-mi-kalaamu & ‘big pens’' \\
\hline
\end{tabular}

The paradigm in (43) is the standard paradigm for Class $9 \mathrm{~b}$ nouns. The paradigm in (44) is that found with Swahili loans which have an initial homorganic cluster. The diminutive and augmentative paradigms in (44) show that the root is ndeeche, whereas if the loan were a standard Class $9 \mathrm{~b}$ form, then the root should be teeche. It may be noted that the class prefixes in the diminutive and augmentative paradigms are short, as predicted by the analysis proposed in this paper. The plural Class $10 \mathrm{~b}$ form is underlyingly $\boldsymbol{\emptyset}$-tsiiny-ndeeche. As Kisa does not permit NN sequences, the paper posits that the nasal of the prefix is deleted. Similarly, for the singular Class $9 \mathrm{~b}$ form, the paper posits that the input is $\mathbf{i}-$ ny-ndeeche, and that parallel to the plural, the prefix nasal is deleted, leaving no actual substantive noun class prefix. However, it may be noted that the output form i- $\varnothing$-ndeeche is identical to a Class 9a singular (45). The Locative forms of these loans with initial NC sequences show the Class $9 \mathrm{~b}$ patterning.

(46) mu-u-Ø-ndeeche mu-Ø-ndeeche shiina in-AUG-9b-plane in-9b-plane which 'in the plane' 'in which plane?'

The locatives of loans in Classes 9c and 9d show the same patterning.

(47) mu-u-m-buuk-a mu-m-buuk-a shiina

$\begin{array}{ll}\text { in-AUG-9c-book-INF } & \text { in-9c-book-INF which } \\ \text { 'in the booking style' } & \text { 'in which booking style?' } \\ \text { mu-u-nz-alaaw-a } & \text { mu-nz-alaaw-a shiina } \\ \text { in-AUG-9d-allow-INF } & \text { in-9d-allow-INF which } \\ \text { 'in the allowing style' } & \text { 'in which allowing style?' }\end{array}$

The Locative forms of Class 9b/c/d loans, and the short Class prefixes in the Diminutive and Augmentative paradigms in 0 , show that alternate stem selection is synchronically active in Kisa.

\section{CONCLUSION}

The paper has provided evidence that there is a synchronically active preference for NC sequences to be preceded by long vowels in Kisa - the VVNC target. This appears to be the most reasonable analysis of the patterning of vowels before NC sequences in loans. It is the only evident motivation for the selection of an alternate stem in Class 9b/c/d/ Locatives, a pattern which is also active in loans. Given that VVNC is a synchronically active target, it requires a synchronic analysis.

However, the fact that one of the ways in which the VVNC target can be attained is through alternate stem selection means it is not possible to exhaustively account for attainment of that target by a phonologically motivated analysis. Consequently, compensatory lengthening analyses cannot provide a complete account of the VVNC target in Kisa. Given that non-compensatory analyses of VVNC are required for general phonological theory in any case, there is no advantage to a compensatory lengthening analysis for Kisa.

As Downing (2005) points out the requirement for non-compensatory analyses of VVNC raises a question about the advantage of compensatory lengthening analyses in Bantu. The Kisa data raises this question in a perhaps more acute form. As illustrated in this paper, the phonology and morphology of Kisa conform to the general patterns of Bantu. It is not the case that Kisa displays a wide range of unusual, sui generis phonological and morphological patterns and/or structures. Therefore, it would appear that any overview analysis of the VVNC preference in Bantu should include the Kisa data. As such, the advantage of compensatory lengthening analyses in Bantu generally is in question.

\section{REFERENCES}

[1] Clements, G. (1986). Compensatory lengthening and consonant gemination in Luganda. In L. Wetzel \& E. Sezer (eds), Studies in compensatory lengthening, 37-77. Dordrecht: Foris.

[2] Downing, L. (2005). On the ambiguous segmental status of nasals in homorganic NC sequences. In M. van Oostendorp \& J. van de Weijer (eds), The internal organization of phonological segments, 183-216. Berlin \& New York: Mouton de Gruyter.

[3] Hubbard, K. (1995). 'Prenasalied consonants' and syllable timing: evidence from Runyambo and Luganda. Phonology 12:235256.

[4] Hyman, L. M. (1992). Moraic mismatches in Bantu. Phonology 9:255-265. 
[5] Maddieson, I. \& P. Ladefoged. (1993). Phonetics of partially nasal consonants. In M. Huffman \& R. Krakow (eds), Nasals, nasalization and the velum, 251-301. San Diego: Academic Press.

[6] Odden, D. (1996). The phonology and morphology of Kimatuumbi. Oxford: Oxford University Press.

[7] Tak, J.-Y. (2003). Prenasalised consonants in Bantu: a cluster or a unit in Optimality Theory. Studies in Phonetics, Phonology and Morphology 9:499-513.

[8] Tak, J.-Y. (2011). Universals of prenasalized consonants: phonemic or derived, single or complex? Journal of Universal Language 12:127-158.

Emily Ayieta Ondondo, PhD, studied Linguistics at the University of Newcastle, New South Wales, Australia. She is LECTURER of Linguistics at Jaramogi Oginga Odinga University of Science and Technology (JOOUST), Kenya. She was formerly LECTURER of Linguistics, Pwani University, Kenya, Kigali Institute of Education, Rwanda, VISITING LECTURER, National University of Rwanda and CASUAL LECTURER, University of Newcastle, Australia. She has authored: The Kisa Verb Phrase. International Journal of English Language and Linguistics Research, 3(5), 9-24, United Kingdom: European-American Journals, 2015. The Kisa Noun Phrase. Us-China Foreign Language, 13(10), 687-700, New York: David Publishing Company, 2015. Acquired Language Disorders as Barriers to Effective Communication. Theory and Practice in language Studies, 5(7), 1324-1329, United Kingdom: Academy Publication, 2015. Effects of Communication Impairments on Knowledge Acquisition, Us-China Foreign Language, 24(10):805-813, New York: David Publishing Company, 2014. Kisa Part-of-Speech Classes: A Morphological Perspective. Germany: Lambert Academic Publishing, 2013. Lexical Cohesiveness in Kisa: Textuality and Text Organisation. Germany: Lambert Academic Publishing, 2013. She is interested in research in Bantu and African Linguistics: Documentation, Phonetics, Phonology, Morphology, Syntax, Lexicography and Lexical Computing. Dr. Ondondo is a registered and active member of Australian Linguistic Society and the Linguistic Society of America. 